\title{
OPTIMASI SISTEM PERSEDIAAN BAHAN BAKU PT. TC
}

\author{
DANIEL SEMBIRING \\ Institut Teknologi Indonesia, Serpong \\ ANDRI \\ Program Studi Informatika \\ Fakultas Teknik, dan Ilmu Komputer \\ Universitas Indraprasta PGRI \\ Email: andriecitra@yahoo.com, Daniel.36679@yahoo.co.id
}

Jl. Nangka No. 58 C, Tanjung Barat, Jagakarsa, Jakarta Selatan 12530

\begin{abstract}
In operation in PT TC has a control system in which the materials available material has significant costs each year so that researchers try to examine that it could not happen. In this study were discussed in detail is the A grade material for class A material has a high percentage is $94.29 \%$. A class of materials is the PAC $8 \mathrm{C}$ which is one of the materials used every second and for 24 hours non-stop to produce water. Then the author forecasting material needs in coming years carried out by the method of forecasting the moving average (Moving Average) and results tracking signal is positive, it means the material needs of the coming year are greater than they are today. Tracking signal obtained still included within the limits of \pm 4 means that the reliability of forecasting acceptable. Comparison inventory system that has been applied in the company with inventory system models Economic Order Quantity, P, and Min - Max do to make it look which system is better. From the comparison of the three models obtained EOQ method is the inventory control system that is the best because it can save the cost of Rp $162,085,358$.
\end{abstract}

Keywords: Economic Order Quantity, System P, Min - Max, ABC Classification

\section{PENDAHULUAN}

Untuk dapat mendapatkan posisi yang kuat maka industri harus meminimalkan biaya produksi yang dikeluarkan agar produk atau jasa yang dihasilkannya memiliki biaya produksi yang seminimal mungkin. Salah satu faktor yang dapat mempengaruhi biaya produksi secara signifikan adalah biaya atas persediaan (inventory) yang dimiliki PT TC. Biaya persediaan (inventory cost) sendiri dapat terdiri atas biaya penyimpanan, biaya pemesanan dan biaya per unit.

PT. TC adalah perusahaan yang bergerak di bidang 'Water Services \& Management', merupakan perusahaan pertama di Indonesia yang bermitra dengan Perusahaan Daerah dalam pengoperasian \& Pemeliharaan Pengolahan Air Minum. PT. TC didirikan pada tahun 1996 bersamaan dengan di tandatanganinya kontrak kerjasama dengan Perusahaan Daerah Air Minum Kabupaten Dati II Tangerang (saat ini telah berganti nama menjadi PDAM Tirta Kerta Raharja Kabupaten Tangerang) dalam Pengelolaan Instalasi Pengolahan Air Minum Cisadane Serpong milik PDAM Tirta Kerta Raharja Kabupaten Tangerang kapasitas 3000 L/det.

Lingkup kerja dan tanggung jawab PT. TC dalam kerjasama pengelolaan ini adalah menjamin Instalasi Pengolahan Air Minum Cisadane Serpong dapat berproduksi secara kontinyu selama 24 jam per hari dengan kualitas air minum yang dihasilkan sesuai standar air minum yang dikeluarkan oleh Menteri kesehatan RI serta kuantitas yang disepakati dengan pihak PDAM Tirta Kerta Raharja Kabupaten Tangerang.

PT. TC sebagai produsen air bersih tidak terlepas dari permasalahan sistem persediaan. Perusahaan ini masih membuat persediaan yang terlalu berlebih yang dapat menyebabkan tertimbunnya uang pada persediaan bahan baku. Dasar penetapan persediaan berlebih yang dilakukan perusahaan adalah sebagai berikut: a). untuk mengantisipasi perubahan pada permintaan dan penawaran, b). menghilangkan/mengurangi risiko keterlambatan pengiriman bahan,c). menghilangkan/mengurangi resiko kenaikan harga, d). mengantisipasi permintaan 
yang dapat diramalkan,dan e) mendapatkan keuntungan dari quantity discount. Dari studi pendahuluan diperoleh data bahwa kelebihan bahan baku koagulan tahun 2015 sebesar 55.245 $\mathrm{kg}$ dan pada tahun 2016 sebesar $56.100 \mathrm{~kg}$.

Kegiatan pengendalian kebutuhan persediaan bahan baku dimaksudkan agar perusahaan selalu pada posisi yang siap melayani pengadaan bahan baku baik dalam keadaan normal maupun pemesanan secara mendadak serta target produksi dapat tercapai secara kontinyu dan seimbang. Dalam perencanaan dan pengendalian persediaan, keputusan-keputusan yang diambil harus sesuai dengan jumlah bahan baku yang diperlukan dan kapan pemesanan dilakukan, dan diharapkan mempunyai faktor biaya yang minimal sehingga dapat dilakukan penghematan bagi perusahaan. Oleh sebab itu, perencanaan dan pengendalian bahan baku harus diusahakan, sehingga tercapai suatu kondisi persediaan yang optimal, yaitu kondisi persediaan terbaik tidak lebih maupun kurang.

Koagulan merupakan bahan baku utama dalam proses penjernihan air yang digunakan setiap hari dalam jumlah yang banyak dibandingkan dengan bahan baku lainnya. Koagulan terdiri dari berbagai merek sesuai dengan penamaan pemasok dan memiliki kandungan zat yang berbeda untuk tiap mereknya.

Ketidakpastian jumlah dan waktu permintaan, lead time dan jumlah serta penyelesaian produksi merupakan masalah yang sering terjadi. Ketidakpastian ini dapat menyebabkan kehabisan persediaan atau sebaliknya jumlah persediaan yang terlalu banyak. Resiko kehabisan persediaan antara lain disebabkan oleh hal-hal seperti permintaan yang lebih besar, Lead time bertambah, Permintaan terlalu tinggi dan waktu ancang bertambah

Untuk mengantisipasi ketidakpastian tersebut, khususnya dalam permintaan dan lead time, maka disediakannya suatu jumlah tertentu (safety stock = SS) yang akan mengurangi resiko kehabisan persediaan. Semakin besar safety stock-nya maka kemungkinan kehabisan persediaan semakin kecil. Akan tetapi, akibatnya adalah biaya simpan semakin besar karena jumlah total persediaan meningkat. Bila demikian, tujuan minimalisasi total biaya persediaan tidak tercapai karena total biaya dalam model persediaan tradisional didapatkan pada titik keseimbangan antara kelebihan dan kehabisan persediaan.

Biaya kelebihan persediaan relatif lebih mudah diperkirakan daripada biaya kehabisan persediaan. Karena sulitnya memperkirakan biaya kehabisan persediaan secara tepat, maka biasanya manajemen menentukan ukuran safety stock berdasarkan tingkat pelayanan (service level) tertentu yang harus diberikan kepada konsumen. Sebagai contoh, bila manajemen menetapkan service level adalah $90 \%$, maka bagian persediaan harus berusaha agar paling banyak dari 10 kali permintaan yang datang hanya 1 kali permintaan yang tidak dapat dipenuhi. Penentuan berapa jumlah safety stock yang dapat memenuhi service level tertentu yang diberikan adalah tergantung dari model persediaannya, yaitu model $\mathrm{Q}$ atau model $\mathrm{P}$.

Hasil pengamatan diperoleh banyaknya volume material yang statusnya sebagai stock dan siklus pemakaian untuk produksi sangat jarang dan tergantung cuaca sehingga terjadi penimbunan material di gudang. Penimbunan biaya pada stok persediaan koagulan disebabkan karena kelebihan stok persediaan koagulan. Selama ini pemesanan koagulan yang dilakukan hanya berdasarkan kebiasaan saja yaitu membeli bahan baku koagulan untuk dijadikan stok tanpa adanya perhitungan sebagaimana bahan baku dapat dijadikan stock sesuai kebutuhan produksi. Hal ini yang menimbulkan permasalahan penimbunan biaya pada persediaan bahan baku koagulan.

\section{METODE}

Studi lapangan merupakan langkah awal dari penelitian, dengan melihat secara langsung keadaan perusahaan serta kegiatan-kegiatan yang berlangsung dalam proses pengadaan bahan baku. Dalam studi lapangan juga dicari permasalahan yang dialami oleh perusahaan, serta mencari data dan fakta secara visual tentang akar permasalahan yang memungkinkan menjadi latar belakang timbulnya permasalahan tidak dalam sistem persediaan. 
Langkah selanjutnya adalah mempelajari teori-teori yang berkaitan dengan permasalahan yang terjadi dalam perusahaan yaitu perusahaan untuk dapat mengendalikan sistem persediaan hingga kondusif untuk pelaksanaan proses produksi. Studi literatur merupakan modal untuk menyelesaikan permasalahan secara sistematis. Dalam studi literatur dicari juga formula dan metode pemecahan masalah yang terjadi secara efektif dan efisien.

Dalam melaksanakan penelitian salah satu hal yang terpenting dan perlu mendapatkan perhatian adalah perumusan dan pembatasan masalah yang dibahas dalam penelitian. Maka perumusan dan pembatasan masalah harus jelas dalam melakukan langkah-langkah selanjutnya agar dapat berjalan dengan sistematis.

Adapun pokok dari permasalahan yang dibahas adalah perlunya dilakukan minimasi atas tingkat persediaan material dan persediaan produk jadi melalui penentuan jumlah persediaan yang optimal mencakup kuantítas yang harus disediakan dalam rentang waktu yang tepat sehingga dapat dicapai minimasi biaya persediaan.

Penelitian bertujuan untuk meneliti proses pengendalian persediaan bahan baku yang berjalan di PT. TC telah lebih baik bila ditinjau dari sudut analisa statistik Proses control, Menentukan metode apa yang sebaiknya digunakan dalam melakukan pengendalian persediaan bahan baku, Memperbaiki stok persediaan bahan baku menjadi lebih effisien dan optimal., serta melakukan analisis biaya untuk menentukan optimalisasi biaya persediaan bahan baku.

Pengumpulan data yang dilakukan terdiri atas data umum perusahaan, data spesifikasi bahan, data persediaan, data pemakaian, dan data pembiayaan. Adapun data lain yang dikumpulkan diantaranya adalah daftar harga koagulan, kapasitas penyimpanan persediaan bahan baku, data sistem reorder point, lead time, dan data pengiriman bahan.

Pengolahan data yang dilakukan dimulai dari perhitungan rata-rata persediaan dan pemakaian material. Dari hasil yang diperoleh kemudian dilakukan klasifikasi ABC untuk menentukan prioritas bahan. Selanjutnya untuk material koagulan PAC 8C dilakukan perhitungan dengan menggunakan sistem $\mathrm{Q}$ dan sistem P. pada sistem Q ditentukan EOQ (Economic Order Quantity), safety stock, dan ROP (Re-Order Point). Dan pada sistem P ditentukan interval review optimal, safety stock, dan target persediaan.

Analisa dibuat untuk melihat dan menilai usulan perbaikan sistem persediaan yang baru. Dengan menggunakan analisa fishbone diupayakan untuk menganalisa akar permasalahan dari faktor 5M (Man, Machine, Material, Method, and Money) dan analisa biaya. Selanjutnya diajukan usulan perbaikan dari faktor $5 \mathrm{M}$ tersebut dengan menggunakan metode $5 \mathrm{~W}+1 \mathrm{H}$.. Analisa dilakukan terhadap data yang telah dikumpulkan maupun yang telah diolah guna menyelesaikan masalah yang diteliti.

Kesimpulan dibuat dari pembahasan masalah hingga analisa dan saran-saran sebagai pelaksanaan perbaikan sistem persediaan yang diajukan oleh peneliti. Saran yang disampaikan disini dengan harapan agar dapat dipergunakan oleh perusahaan PT. TC sebagai dasar pertimbangan dalam melakukan langkah - langkah perbaikan selanjutnya di masa yang akan datang

\section{HASIL DAN PEMBAHASAN}

Untuk meramalkan permintaan yang akan datang penulis menggunakan model peramalan rata-rata bergerak (Moving Average), model rata - rata bergerak terbobot (Weighted Moving Averages Model, dan model pemulusan eksponensial (Exponential Smoothing Model). Setelah dilakukan perbandingan hasil peramalan permintaan produksi air dengan 3 model tersebut maka model yang dipilih adalah model rata - rata bergerak (Moving Averages Model) menggunakan rata - rata bergerak 4-periode. Metode tersebut dipilih karena memiliki nilai MAD terkecil. Peta kontrol tracking signal dari model tersebut juga menunjukkan bahwa nilai - nilai tracking signal berada dalam batas - batas pengendalian yaitu maksimum \pm 4

Jenis material yang ada diperusahaan sebanyak 4 jenis material yang terdiri dari bahan kimia yang berupa padatan dan cairan. Untuk mengatur pengendalian persediaan material tersebut, maka dilakukan pengelompokan material menurut volume biaya yang ditimbulkan 
selama periode waktu 1 tahun. Material yang masuk dalam kategori kelas A adalah material yang akan dibahas lebih detail pada penelitian ini karena persentase volume penggunaan uang lebih besar dari pada persentase penggunaan uang kelas B dan C. Pada klasifikasi ABC pemakaian material dapat dilihat pada gambar 1.

Meramalkan permintaan yang akan datang penulis menggunakan model peramalan rata-rata bergerak (Moving Average), model rata - rata bergerak terbobot (Weighted Moving Averages Model, dan model pemulusan eksponensial (Exponential Smoothing Model). Setelah dilakukan perbandingan hasil peramalan permintaan produksi air dengan 3 model tersebut maka model yang dipilih adalah model rata - rata bergerak (Moving Averages Model) menggunakan rata rata bergerak 4-periode. Metode tersebut dipilih karena memiliki nilai MAD terkecil. Peta kontrol tracking signal dari model tersebut juga menunjukkan bahwa nilai - nilai tracking signal berada dalam batas - batas pengendalian yaitu maksimum \pm 4

Jenis material yang ada diperusahaan sebanyak 4 jenis material yang terdiri dari bahan kimia yang berupa padatan dan cairan. Untuk mengatur pengendalian persediaan material tersebut, maka dilakukan pengelompokan material menurut volume biaya yang ditimbulkan selama periode waktu 1 tahun. Material yang masuk dalam kategori kelas A adalah material yang akan dibahas lebih detail pada penelitian ini karena persentase volume penggunaan uang lebih besar dari pada persentase penggunaan uang kelas B dan C. Pada klasifikasi ABC pemakaian material dapat dilihat pada grafik dibawah ini :

Tabel 1. Persentase Volume Biaya Material Berdasarkan Klasifikasi ABC

\section{Klasifikasi material}

Persentase volume

biaya setiap kelas Presentasi kumulatif (\%)

$(\%)$

\begin{tabular}{llcc}
\hline A & PAC 8C & 94.29 & 94.29 \\
B & Gas Khlorin & 4.83 & 99.12 \\
C & Magnaflok \& & 0.88 & 100.00
\end{tabular}

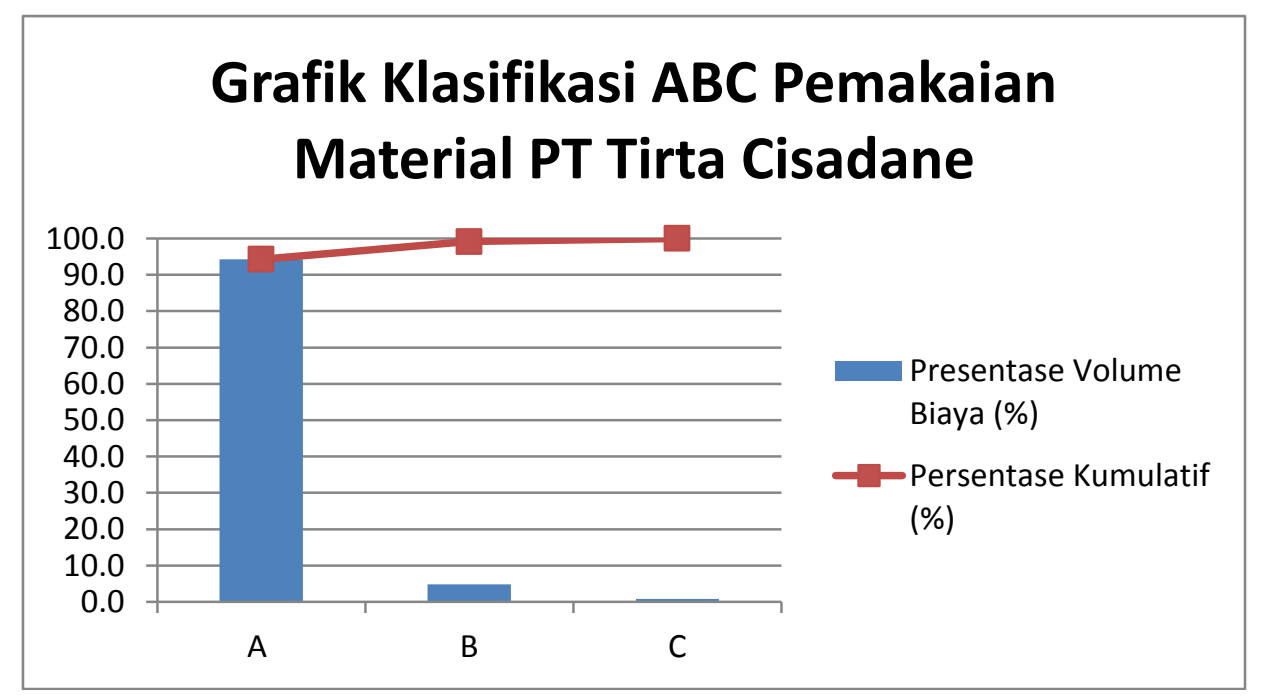

Gambar 1. Grafik Klasifikasi Pemakaian Material PT TC

Berdasarkan pengumpulan dan pengolahan data pada klasifikasi $\mathrm{ABC}$ dapat dilihat hasil pengelompokkan dan besarnya persentase nilai penggunaan uang pertahun dari masing masing kelompok material yaitu kelompok A yang terdiri dari PAC 8C sebesar 94.29\% dengan nilai 
uang Rp 9,064,147,600, kelompok B yang terdiri dari Gas Khlorin sebesar 4.83\% dengan nilai uang Rp 464,447,500, dan kelompok C yang terdiri dari kapur dan magnaflok sebesar $0.88 \%$ dengan nilai uang $\operatorname{Rp} 84,461,215$.

Pada penelitian ini yang dibahas secara detail adalah sebatas material kelompok A karena persentase nilai penggunaan uangnya mencapai $94.29 \%$ dari total penggunaan nilai uang. Kemudian hasil pengolahan peramalan permintaan produksi ditahun yang akan datang terlihat lebih besar kebutuhannya, hal tersebut dapat dilihat dari nilai dan kecenderungan grafik tracking signal yang bernilai positif.

Berdasarkan pengumpulan dan pengolahan data perbandingan sistem persediaan yang telah dilakukan didapat hasil seperti tabel dibawah ini :

Tabel 2. Jumlah Persediaan dan Biaya Berdasarkan Sistem Persediaan

\begin{tabular}{|c|c|c|c|c|c|c|}
\hline \multirow{2}{*}{$\begin{array}{c}\text { No } \\
\text {. }\end{array}$} & \multirow{2}{*}{$\begin{array}{c}\text { Paramet } \\
\text { er }\end{array}$} & \multirow{2}{*}{$\begin{array}{c}\text { satua } \\
\text { n }\end{array}$} & \multicolumn{4}{|c|}{ Metode } \\
\hline & & & $\mathbf{Q}$ & $\mathbf{P}$ & Min Max & Perusahaan \\
\hline 1 & EOQ & $\mathrm{Kg}$ & 12454 & - & - & 20000 \\
\hline 2 & $\begin{array}{l}\mathrm{P} \\
\text { (interval) }\end{array}$ & Hari & - & 1.63 & - & . \\
\hline 3 & ROP & $\mathrm{Kg}$ & 23157.23 & - & - & 45000 \\
\hline 4 & $\begin{array}{l}\text { SS } \\
\mathrm{T} \text { (Target }\end{array}$ & $\mathrm{Kg}$ & 0.17 & 0.21 & - & 45000 \\
\hline 5 & Inventory & $\mathrm{Kg}$ & - & 34735.8 & - & - \\
\hline 6 & Min & $\mathrm{Kg}$ & - & - & $23,157.23$ & . \\
\hline 7 & Max & $\mathrm{Kg}$ & - & - & $35,611.23$ & - \\
\hline 8 & $\mathrm{TC}$ & $\mathrm{Rn}$ & $10,604,243,00$ & $10,606,361,84$ & $10,604,361,70$ & $10,770,578,36$ \\
\hline
\end{tabular}

Pada perbandingan sistem pengendalian persediaan material dapat dilihat bahwa sistem $\mathrm{Q}$ memiliki nilai biaya sebesar Rp 10,604,243,007.8, system P memiliki nilai biaya sebesar Rp $10,606,361,846.2$, system min - max memiliki nilai biaya sebesar Rp 10,604,361,705.8, dan sistem perusahaan memiliki nilai biaya sebesar $\mathrm{Rp}$ 10,770,578,365.6. dari perbandingan keempat sistem tersebut nilai biaya terbesar untuk pengendalian material adalah dengan menggunakan sistem perusahaan sebesar Rp 10,770,578,365.6 dan nilai biaya terkecil untuk pengendalian material adalah system Q sebesar Rp 10,604,243,007.8. Dari data tersebut artinya penerapan sistem pengendalian material di PT TC masih bisa dilakukan perbaikan.

\section{PENUTUP}

\section{Simpulan}

Pada hasil dan pembahasan yang telah dilakukan maka diperoleh kesimpulan berikut.

1. Pada sistem pengendalian persediaan bahan baku di PT TC belum mengacu kepada suatu referensi yang ilmiah hal ini terlihat dari cara penentuan safety stock dan titik pemesanan kembali (ROP) yang nilainya sama besar yaitu 45,000 Kg dan hal ini menyebabkan total biaya persediaan menjadi tinggi, yaitu sebesar Rp 10,770,578,365.6.

2. Dari perbandingan sistem persediaan model Q, P, dan Min - Max dapat dilihat besarnya biaya yang dikeluarkan paling kecil adalah sistem persediaan model EOQ dengan biaya sebesar Rp 10,604,243,008. Artinya dengan metode ini total biaya menjadi optimal, dimana kuantitas pemesanan bahan baku sebesar $12.454 \mathrm{~kg}$ dan waktu pemesanan bahan baku dilakukan pada saat stok bahan baku di gudang sebesar $23.157,23 \mathrm{~kg}$ 
3. Metode persediaan yang terbaik adalah metode persediaan dengan model EOQ karena perusahaan dapat menghemat biaya persediaan sebesar Rp 162,085,358. Sedangkan dengan model $\mathrm{P}$ menghemat biaya persediaan sebesar $\mathrm{Rp}$ 159,966,519 dan jika menggunakan model Min-Max perusahaan dapat menghemat biaya sebesar Rp 161,966,660.

\section{Saran}

Untuk melakukan penghematan biaya persediaan, berikut saran yang diusulkan.

1. Penulis mengusulkan untuk menerapkan sistem pengendalian persediaan dengan menggunakan model EOQ karena telah dikaji secara ilmiah bahwa model EOQ dapat menghemat biaya persediaan bahan baku sebesar Rp 162,085,358 per tahun.

2. Perusahaan diharapkan mempertimbangkan untuk memberikan training kepada devisi pembelian/produksi untuk melakukan perbaikan pada sistem pengendalian persediaan seluruh material.

3. Penulis juga mengusulkan supaya kualitas dari material koagulan dapat ditingkatkan standar kualitas penerimaan material dan dibandingkan efektivitas dan efisiensi material koagulan tersebut sebelum dan sesudah peningkatan standar kualitas material, karena kualitas material juga salah satu penyebab yang dapat menyebabkan biaya persediaan menjadi tinggi.

\section{DAFTAR PUSTAKA}

Aleph, Geoff , 2014, Inventory Management: Advanced Method for Managing Inventory within Business System , John Wiley \& Son; Inc, NJ, USA.

Jonsson, P and Mattsson, S, 2014, A Longitudinal Study of material planning application in Manufacturing Companies, International Journal of Operations Production Management, 26, pp 971-995. .

Djunaidi, P, S, 2014, Pengaruh Perencanaan Pembelian Bahan Baku dengan Model EOQ untuk Multi Item dengan All Unit Discount, Jurnal Ilmiah Teknik Industri. 4, 8694, IMTI, Jakarta.

Fithri Prima, Annise Sindikia. 2014. Pengendalian Persediaan Pozzolan di PT Semen Padang. Padang, 3, 665-685, Jurnal Optimasi Sistem Industri. Universitas Andalas, Padang.

Gaspersz, Vincent, 2005, Production Planning and Inventory Control Berdasarkan Pendekatan Sistem Terintegrasi MRP II dan JIT menuju Manufakturing 21, PT.Gramedia Pustaka Utama, Jakarta.

Indroprasto, Erma Suryani, 2014, Analisis Pengendalian Persediaan Produk Dengan Metode EOQ Menggunakan Algoritma Genetika untuk Mengefisiensikan Biaya Persediaan, 1, A305-40, Jurnal Teknik ITS, ITS.

Nasution, A.H dan Y. Prasetyawan, 2015, Perencanaan dan Pengendalian Produksi, Graha Ilmu, Yogyakarta.

Pujawan, N, 2015, Supply Chain Management, Guna Wijaya, Surabaya.

Ristono, A, 2014, Manajemen Persediaan, Graha Ilmu, Yogyakarta.

Relph, G.J, 2014, Inventory Management in Business System, Phd thesis, Manchester University.

Waters, D, 2014, Inventory Control and Management, Kogan Page, London.

Waters, D, 2015, Global Logistic and Distribution Planning, Kogan Page, London. 